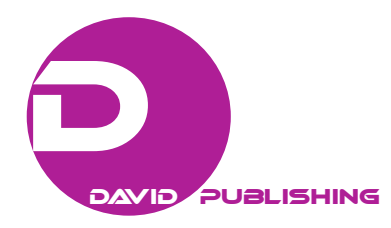

\title{
All From the Fountainhead on Preconditions for Talents to Emerge
}

\author{
Xiaolin Jin \\ University of Leeds, Leeds, UK
}

\begin{abstract}
This paper is designed to analyze the relation between developing superior human resource, which is called talents and has wider and more upscale effect in the society, and the system and mechanism improving including policies formulation, culture building, and organization structuring. An amount of evidences sorted from Chinese history have been used for evidencing the method how system and mechanism exert impact on selection and development. Meanwhile concerning about system and mechanism of China in the present, the paper provides some feasible suggestion that something would better be recomposed as the fact needs. The first part of the paper explains the practical meaning of the point mentioned in the title, then reviews how system and mechanism exerted influence on the talents in distinct periods of China. Secondly, it used historical materialism to analyze the preconditions for talents to emerge and flow. At last, the paper derived the conclusion of the relationship.
\end{abstract}

Keywords: talent, history, system and mechanism

Talents are the vigor of a nation, the precondition of a country's splendid achievement, the motivation of a society's advancement, and the representation of every single person's value. Therefore, individuals expect themselves to be talents, institutions want to gather talents together, and societies try to make talents as groups. These dreams are everlasting in the history of human being. In order to remove the ideological and institutional obstacles that prevent talents from developing themselves in China, it is needed to liberate and strengthen the vigor of talents and to form an institutional advantage which is internationally competitive in terms of managerial, working, and organizational arrangement. The basic direction for the reform should be outcome-oriented to encourage talents, to provoke competitions, and to develop a reciprocal and supportive environment. This is the power that China owns to stimulate the vigor of talents.

\section{History Makes Us Think About How the System and Mechanism of Talents Develop}

There several significant phenomena which deserve attention in the field of talents:

First, let us compare different historical periods in Chinese history. The periods which witness the explosion of talents include the Spring and Autumn Warring State period ${ }^{1}$, the Three Kingdoms period ${ }^{2}$, and the Open and Reform period. These eras are when old system is replaced by a new one. Spring and Autumn is

Corresponding author: Xiaolin Jin, postgraduate, Human Resource Management, University of Leeds, Leeds, UK; research fields: human resource management, employment relationship, training and development.

1 The Spring and Autumn Warring State period: Chinese history from approximately 771 to $476 \mathrm{BC}$ (or according to some authorities until $403 \mathrm{BC}$ ) which corresponds roughly to the first half of the Eastern Zhou Period.

2 The Three Kingdoms (220-280 AD) was the tripartite division of China between the states of Wei, Shu, and Wu. It started with the end of the Han dynasty and was followed by the Jin dynasty. 
the time for talents. During that period, a great number of philosophers influenced China by their moral and political theories. At the end of Han Dynasty ${ }^{3}$, a lot of great figures including Cao Cao ${ }^{4}$, Zhuge Liang ${ }^{5}$, Sun Quan ${ }^{6}$, Sima $\mathrm{Yi}^{7}$, Zhou $\mathrm{Yu}^{8}$, and Liu Bei ${ }^{9}$ left their own strokes in history, sometimes from a menial start. At the end of Qin, Yuan ${ }^{10}$, Ming ${ }^{11}$, and Qing dynasties ${ }^{12}$, along with the Open and Reform period after the establishment of People's Republic of China (PRC), there are all significant explosions of talents.

Second, let us look at the class origin of the historical figures. During the times in which many talented people show up, there are always a lot of chances for people with low class origins to become big names through their courage and efforts. For example, Bai $\mathrm{Qi}^{13}$, a famous $\mathrm{Qin}^{14}$ general, came from an ordinary family. He joined the army at the age of 15 and fought more than 70 wars, including the War of Changping, a famous war between Qin and Zhao ${ }^{15}$ (260 BC). The result of the war was that around 200,000 Zhao soldiers were buried and killed. The leader of Zhao army was Zhao Kuo ${ }^{16}$, a person who had no experiences in army. The reason why he was chosen as the general was that he had an aristocratic family background. In contrast, Qin elites have two main origins: civilians and foreigners. Shang Yang ${ }^{17}$ is not from Qin originally. His original name is Wei Yang because his former nationality is $\mathrm{Wei}^{18} . \mathrm{Li} \mathrm{Si}^{19}$, the prime minister of Qin, was an

\footnotetext{
3 The Han dynasty: The second imperial dynasty of China (206 BC-20 AD), proceeded by the Qin dynasty (221-206 BC) and succeeded by the Three Kingdoms period (220-280 AD).

${ }^{4}$ Cao Cao (c. 155-15 March 220): A Chinese warlord and the penultimate Chancellor of the Eastern Han dynasty who rose to great power in the final years of the dynasty. He has also been praised as a brilliant ruler and military genius.

5 Zhuge Liang (181-234): A Chinese politician, military strategist, writer, engineer and inventor. He served as the chancellor and regent of the state of Shu Han during the Three Kingdoms period.

${ }^{6}$ Sun Quan (182-21 May 252): The one formally known as Emperor Da of Wu (literally "Great Emperor of Wu"), was the founder of the state of Eastern Wu during the Three Kingdoms period.

${ }^{7}$ Sima Yi (179-251): A military general, government official and regent of the state of Wei during the Three Kingdoms period of China.

${ }^{8}$ Zhou Yu (175-210): A military general and strategist serving under the warlord Sun Ce in the late Eastern Han dynasty of China.

9 Liu Bei (161 223): A warlord in the late Eastern Han dynasty who founded the state of Shu Han in the Three Kingdoms period and became its first ruler.

${ }^{10}$ The Yuan dynasty (1271-1368): The Great Yuan was the empire or ruling dynasty of China established by Kublai Khan, leader of the Mongolian Borjigin clan.

${ }_{11}$ The Ming dynasty: The ruling dynasty of China-then known as the Great Ming Empire-for 276 years (1368-1644) following the collapse of the Mongol-led Yuan dynasty.

${ }_{12}$ The Qing dynasty: The Great Qing, was the last imperial dynasty of China. It was established in 1636, and ruled China proper from 1644 to 1912 .

${ }_{13}$ Bai Qi (c. 332 BC-257 BC): A military general of the Qin state in the Warring States period of China. He was named by Chinese historians as one of the four greatest generals of the Warring States period.

${ }^{14}$ Qin (897 BC-207 BC): An ancient Chinese state during the Zhou dynasty. Traditionally dated to 897 BC, it took its origin in a reconquest of Western lands previously lost to the Rong; its position at the western edge of Chinese civilization permitted expansion and development that was unavailable to its rivals in the North China Plain.

${ }^{15}$ Zhao (403 BC-222 BC): One of the seven major states during the Warring States period of ancient China. It was created from the three-way Partition of Jin, together with Han and Wei, in the 5th century BC.

${ }^{16}$ Zhao Kuo (died 260 BC): A general of the State of Zhao in Warring States period. He was sent on the orders of King Xiaocheng of Zhao to the battlefield to replace the previous general, the famous commander Lian Po. The King, under the influence of several of his courtiers (many of whom were believed to be bribed by Qin emissaries), and heedless of the advice given by his most important minister, Lin Xiangru, was dissatisfied by Lian's defensive strategy: while Lian Po was in command, he set up camp, built forts, and stayed in them, not responding to any of the enemy's taunts or lures designed to get his army out onto the field. This dragged on for several years, and the King felt that the time for decisive action had come.

${ }_{17}$ Shang Yang (c. 390-338 BCE): A statesman and reformer of the State of Qin during the Warring States period of ancient China. His policies laid the administrative and political foundations that would enable Qin to conquer all of China, uniting the country for the first time and ushering in the Qin dynasty. He and his followers contributed to the Book of Lord Shang, a foundational work of what has modernly been termed Chinese Legalism.

18 Wei: An ancient Chinese state during the Warring States period. Its territory lay between the states of Qin and Qi.

${ }^{19} \mathrm{Li} \mathrm{Si}(280$ BC-208 BC): A Chinese politician of the Qin dynasty, well known Legalist writer and politician, and notable calligrapher.
} 
ordinary official working for Chu. He came to Qin just after completing the course taught by XunZi ${ }^{20}$. In the times of talents explosions, talents are not made on purpose, but transformed from ordinary people. Liu Bang's subordinates who help him to fight against $\mathrm{Chu}^{21}$ and establish Han Dynasty, the 28 generals who help Liu $\mathrm{Xiu}^{22}$ to establish the Eastern Han, the big names of the Three Kingdoms period, Li Shimin's ${ }^{23}$ revolutionary comrades during the end of Sui Dynasty ${ }^{24}$, the significant assistants of Zhu Yuanzhang ${ }^{25}$ to establish Ming Dynasty, and the entrepreneurs of many renowned private enterprises today, are all transformed from ordinary civilians.

Maybe these two phenomena would leave us an impression that "turbulence" brings the explosion of talents. Actually, it is untrue. There are always great talents during peaceful and stable periods, which can be categorized as the third phenomenon. In Chinese history, Han and Wei Dynasty ${ }^{26}$ produce essayists. Tang ${ }^{27}$ and Song Dynasties ${ }^{28}$ produce poets. A diligent emperor attracts political talents, while a great reformist attracts both political and economic ones. For example, the coastal cities, such as Shenzhen have nourished more private enterprise owners compared with many other cities.

\section{Preconditions for Talents to Emerge and Flow Vigorously}

So, how should we view these phenomena?

There is a poem by Gong Zizhen ${ }^{29}$ (Mao, 1992, p. 178):

The reform that China needs should be as swift as thunder It is disappointing that there is no spring of vigor in a banal society I hope the court could be open-minded enough to give more opportunities to the talents we all need.

20 The Xunzi (325 BC-238 BC): An ancient Chinese collection of philosophical writings attributed to XunKuang, a 3rd century $\mathrm{BC}$ philosopher usually associated with the Confucian tradition. The Xunzi is perhaps most famous for the emphasis it places on education and propriety, as well as its striking assertion that "human nature is detestable". The text is furthermore an important source of early theories of ritual, cosmology, and governance. The ideas within the Xunzi are thought to have exerted a strong influence on Legalist thinkers, such as Han Fei, and laid the groundwork for much of Han Dynasty political ideology.

${ }^{21}$ The Xunzi (325 BC-238 BC): An ancient Chinese collection of philosophical writings attributed to XunKuang, a 3rd century $\mathrm{BC}$ philosopher usually associated with the Confucian tradition. The Xunzi is perhaps most famous for the emphasis it places on education and propriety, as well as its striking assertion that "human nature is detestable". The text is furthermore an important source of early theories of ritual, cosmology, and governance. The ideas within the Xunzi are thought to have exerted a strong influence on Legalist thinkers, such as Han Fei, and laid the groundwork for much of Han Dynasty political ideology. Chu (1046 BC-223 BC): A hegemonic, Zhou dynasty era state. With its continued expansion Chu became a great Warring States period power, until it was overthrown by the Qin in $223 \mathrm{BCE}$.

${ }^{22}$ Liu Xiu: Emperor Guangwu (15 January 5 BC-29 March 57), courtesy name Wenshu, was an emperor of the Chinese Han dynasty, restorer of the dynasty in AD 25 and thus founder of the Later Han or Eastern Han (the restored Han Dynasty).

${ }^{23}$ Li Shimin: Emperor Taizong of Tang (28 January 598-10 July 649), personal name Li Shimin, was the second emperor of the Tang dynasty of China, ruling from 626 to 649. Taizong subsequently played a pivotal role in defeating several of the dynasty's most dangerous opponents and solidifying its rule over China.

24 The Sui dynasty (581-618): A short-lived imperial dynasty of China of pivotal significance.

${ }^{25}$ Zhu Yuanzhang (1328-1398): The Hongwu Emperor (21 October 1328-24 June 1398), was the founding emperor of the Ming dynasty.

26 The Northern Wei (420-589): A dynasty founded by the Tuoba clan of the Xianbei, which ruled northern China from 386 to 534 C (de jure until 535), during the period of the Southern and Northern Dynasties. Described as "part of an era of political turbulence and intense social and cultural change", the Northern Wei Dynasty is particularly noted for unifying northern China in 439.

27 The Tang dynasty (618-907) or the Tang Empire: An imperial dynasty of China, preceded by the Sui dynasty and followed by the Five Dynasties and Ten Kingdoms period. Historians generally regard the Tang as a high point in Chinese civilization, and a golden age of cosmopolitan culture.

28 The Song dynasty (960-1279): An era of Chinese history that began in 960 and lasted until 1279, the dynasty was founded by Emperor Taizu of Song following his usurpation of the throne of the Later Zhou, ending the Five Dynasties and Ten Kingdoms period. This dynasty also saw the first known use of gunpowder, as well as the first discernment of true north using a compass.

${ }_{29}$ Gong Zizhen (1792-1841): A Chinese poet, calligrapher and intellectual active in the 19th century whose works both foreshadowed and influenced the modernization movements of the late Qing dynasty. 
This poem represents the call of many people in his time. In terms of the selection and management of talents, "the chief designer" Deng Xiaoping ${ }^{30}$ proposed in 1986 that "it would be good if there were a number of outstanding politicians, economists, militarists and diplomats" (Deng, 1993, p. 179). In order to achieve this goal, Deng proposed that it is needed to "build a ladder for young people and enable them to transcend the hierarchy" (Deng, 1993, p. 284).

The analects and stories which encourage individual efforts are always told from generation to generation. This is a tradition of how we view and deal with the issue of talents. In fact, the development of talents is not an isolated process. Instead, it is influenced and limited by many societal circumstances. If we consider the "court" from Gong's poem as societal factors and consider the "ladder" in Deng's words as institutional factors, it is not god but societal and institutional system that determines the emergence of talents. It is only a well-developed system that could serve as the origin of a vigorous talents flow.

The first phenomenon tells us that to provide everyone with a free environment to show their talents, personalities, interests, and preferences is one of the basic preconditions for talents to emerge. The principle that everyone could be successful proves that talents come from manpower. Human resource has the feature that it could gather itself in the most active way. First, in terms of the unit, volume, and form of resource calculation and transfer, human resource has its own particularity which is related with "individual". In the process of transfer and management, every single talented person cannot be divided or even combine with others. Every "individual" is the biggest and smallest unit at the same time. Second, in terms of the fluidity of resource, human resource has the feature of autonomous flowing, managing, and controlling. As the society develops, the flavor of "resource", which is related with being managed and owned, becomes less and less shown in the field of "human resource". In terms of rights, identity, status, and human dignity, the talents and the users are equal. Third, in terms of how the effects of the resource brings into play, human resource has the feature of being hard to observe and measure from outside. Human resource is determined by both inside and outside factors. Its autonomy and fluidity are always changing into different directions and can be motivated from both material and spiritual dimensions. The value of human resource is not determined by superficial conditions, such as height, weight, sex, age, and diploma. Instead, it is determined by one's intelligence. Fourth, in terms of the production and evaluation of the resource, human resource has the feature of long-term cultivation and accumulation.

The principle shows that the management of talents should enable specific talents to perform in specific fields. The quality and effect of human resource can only be testified by practice. Talents do not only refer to people with special abilities, but also refer to all kinds of people who are able to do something well. There are names, such as "general talents", "artisan talents", "art talents", "rare talents", "strange talents", "weird talents", and so on. This principle is well-illustrated by slangs, such as "Every field can produce a top guy", "Each fairy has a way to cross the sea", and "Foot has its shortage while inch has its length".

The second phenomenon tells us that the institutional factor functions as the guide of talents management. It offers the motivation and orientation of talents demands. The system usually creates a motivating atmosphere with refreshing vigor. "The principle of being successful" shows that talents are made through manpower stimulation. The value of human resource comes from the level of the talents' ability, the degree of their efforts

\footnotetext{
${ }^{30}$ Deng Xiaoping (22 August 1904-19 February 1997): A Chinese politician who was the paramount leader of the People's Republic of China from 1978 until his retirement in 1989. He led China through far-reaching market-economy reforms.
} 
and the stimulation from the environment. Relatively, competition is the cheapest and most effective way for talents to emerge. An open and flexible system is needed to enable the top talents to stand out. From the social tradition of the past, we can see that the obstacles and barriers often come from failing to match talents with their specific advantages. In terms of individual, everyone would experience a process of exploring and strengthening his/her own talents. Wang $\mathrm{Anshi}^{31}$ said that:

The union of six states produced speech talents; the war between 776 Liu Bang and Xiang Yu made military talents; Li Shimin's ambition for Tang Dynasty's prosperity attracted counseling talents. When these leaders hadn't emerged, the talents hadn't shown up either. When the emperors called for them, all the talents came to the court. The concern we have today is that the leader doesn't need or look for the talents. (Wang, 1974, p. 372)

Under the old system, the ruling class' routes and principles could similarly determine the categorization and orientation of the talents. Therefore, the system and mechanism must ensure the flow of talents because the flow is a required precondition for talents to stand out. It is shown by the breakdown of jobs-for-life culture and the fluidity of employment brought by competitions (Tang, 1998, pp. 101-102).

The third phenomenon tells us that mechanism also determines the number of talents in a society. In practice, mechanism refers to how people are managed and transfer by others, which can provide either efficiency or burden. Furthermore, it is a dynamic process to identify the top talents, so does the forming of them. An environment that motivates the autonomy of talents respects the principle of talents' development and the feature of intelligence work. People are always developing from lower level to higher one. When the level has increased, the former working condition and position should be replaced by new ones. If the former institution cannot afford these, talents would flow to another one. Due to the different speeds of every single talent's self-development, restructure and reorganization are always needed. Therefore, the ideal working condition and environment for talents are very diverse and complicated. It would be disappointing to disturb others choices.

In a nutshell, how manpower becomes talents and shows the best is determined by how the system and mechanism are innovated. Just innovating the system and mechanism is the fundamental path to bring the vigor.

\section{To Realize the Specialty of Talents Is the Basis of Talents System Construction}

A liberating environment is needed for manpower to become talents. Basically, the effect of motivation is stronger than that of management. There are three main reasons:

Firstly, both talents and employers cannot have a clear measurement of each other's value. On one hand, the height, weight, and speech ability of a talent can be known at the first time, and the information of diploma and experiences can also be seen from the files; however, it is hard to measure his/her working ability, knowledge and interpersonal skills. On the other hand, it is also difficult for talents to always feel the same about the prospect, condition, environment, and welfare of a certain institution. Therefore, the two main parts of the talents market must have the preparation of always keeping choosing. A complete and normative contract is also needed.

Secondly, the value of human resource, especially the tapping of one's potential, does not only depend on one's own ability and efforts, but also depends on the environment. It would be favorable if encouragement,

\footnotetext{
31 Wang Anshi (8 December 1021-21 May 1086): A Chinese economist, statesman, chancellor and poet of the Song Dynasty who attempted major and controversial socioeconomic reforms known as the New Policies. These reforms constituted the core concepts of the Song-Dynasty Reformists, in contrast to their rivals, the Conservatives, led by the chancellor Sima Guang.
} 
competition, and reeducation are all provided in the environment. Therefore, if the employer offers the condition for talents to completely show their potentials and abilities in all aspects, talents would give it back through outstanding performance. If the environment is not that favorable, maybe the talents would give something else back. To summarize, the fundamental factor to motivate talents is to create "I want" intend of "want me" situations.

Thirdly, a performance-encouraging and outcome-oriented mechanism has unimaginable power to motivate talents. Historical materialism believes that people are made by their environment. Here the notion of environment refers to the politics, economy, and social development of a certain period. However, the degree of how the environment produces talents also depends on people's enthusiasm of their career and the intensity of the competition. During the ancient times, the rise and fall of a dynasty always witness the emergence of a great number of political, economic, cultural, and military talents. A beneficial environment for talents emergence is always to cultivate a tendency for people to compete with each other and pursue material gains. Based on this principle, to change the idea of "organizing, cultivating, and arranging, and promote "performance step system" is the theoretical and social origin of a talents-friendly environment and mechanism. It is also the absolute social basis for top talents to emerge in a great number and to keep emerging in the future.

\section{Conclusions}

To ensure the talent development, an appropriate environment is necessary. As a result, the system and mechanism should be constantly adjusted to the changing market's need.

\section{References}

Deng, M. (2008). Qinhan diwang wenzhi wugong quanshu. Beijing: Haichao Publishing House.

Deng, X. P. (1993). On the reform of the political system. Deng Xiaoping Wenxuan, 1(3), 179.

Deng, X. P. (1994). Reform of the party and state leadership systems. Deng Xiaoping Wenxuan, 2(2), 324.

Deng, X. P. (2004). Deng Xiaoping Nianpu (1975-1997). China: CCCPC Party Literature Publishing House.

Hu, J. T. (2016). Transform China from a country with large human resources into a country with strong human resources. $H u$ Jintao Wenxuan, 1(3), 390.

Jin, S. H., \& Xie, X. H. (1998). Battle of Changping-The investigation of the most huge battle in ancient China. China: Shanxi People's Publishing House.

Long, P. P. (2009). Deng Xiaopin's thought of common prosperity should be read and practiced. In Reread Deng Xiaopin's thought of common prosperity. China: Economy and Science Publishing House.

Mao, Z. D. (1992). Introduce cooperation. Jianguo Yilai Maozedong Wengao, 7, 178.

Tang, M. S. (1998). The relationship between competition and becoming talent should be deposed appropriately. Social Scientist, S2, 101-102.

Wang, A. S. (1974). The theory of material. China: Shanghai People's Publishing House.

Zhu, L. G. (2017). Everyone can innovate. People's Daily, October 23, 2017, p. 14. 